\title{
A Young Woman With Spontaneous Hemothorax
}

\author{
Sukru Gurbuz ${ }^{\mathrm{a}, ~ d}$, Irfan Bayhan ${ }^{\mathrm{a}}$, Muhammet Gokhan Turtay ${ }^{\mathrm{a}}$, \\ Hakki Ulutas $^{\mathrm{b}}$, Zeynep Ayfer Aytemur ${ }^{\mathrm{c}}$
}

\begin{abstract}
Spontaneous hemothorax is defined as blood aggregation due to nontraumatic causes. Pulmonary pathologies, pleural pathologies, lung tumors, stomach pathologies, blood dyscrasia and non-pulmonary intrathoracic pathologies could be the causes of spontaneous hemothorax. It could be widely seen in young ages (average 22.1 and 34.0 years) and often depends on pleural pathologies. A 17-year-old female patient consulted with the complaints of chest pain on the left side and dyspnea. She did not have tachypnea and tachycardia. In the lung exam, there was no rhonchi but there was crackles. Other system exams were normal. Lung graph findings were compatible with left unilateral hemothorax. In computerized tomography, it was found that there were obvious pleural liquids with the depth of 5.5 $\mathrm{cm}$ on the left hemothorax and there were atelectasis in some areas. It was learnt that the patient did not have any diagnosed disease previously, did not use any drugs, did not complain with hemoptysis, and did not have fever in that time. In addition, her family did not have illness and myocardium infarction. Under the consideration of these circumstances, patient was treated to thoracic medicine services with catheter thoracostomy. With expansion deficiency and inappropriate drainage, the patient was implemented left video-assisted thoracoscopic surgery (VATS), pleural biopsy and pleural drainage. In her VATS report, there were pleural liquids, minimal parenchymal units were seperated, thorax was small and diaphragm was elevated and no substantial pleural and parancimal pathologies were not defined. The sample which was taken from the pleural biopsy was fibrinous ploritis and it was compatible with common fresh bleeding. Cytologic findings were compatible chronic inflammatory reaction. Treatment of spontaneous hemothorax differs because of the etiology and in most cases tube thoracostomy could not be enough. Recently, VATS has become popular. In this case, VATS and tube thoracostomy were deployed. In conclusion, hemothorax is an urgent situation which has to be diagnosed immediately. Awareness of causes is highly helpful
\end{abstract}

Manuscript accepted for publication June 03, 2015

${ }^{a}$ Department of Emergency Medicine, Inonu University, Malatya, Turkey ${ }^{b}$ Department of Thoracic Surgery, Inonu University, Malatya, Turkey 'Department of Pulmonary Diseases, Inonu University, Malatya, Turkey ${ }^{\mathrm{d} C}$ Corresponding Author: Sukru Gurbuz, Department of Emergency Medicine, Inonu University, Malatya, Turkey. Email: sukrugurbuz@gmail.com

doi: http://dx.doi.org/10.14740/jmc2198w to diagnose. Even though it is rarely seen in the patients with chest pain and dyspnea, spontaneous hemothorax has to be considered. Treatment methods have to be decided up to vital indications and tube thoracostomy has to be implemented. In the elective situations in which drainage could not be used, VATS would be thought as an alternative option.

Keywords: Spontaneous; Hemothorax; VATS

\section{Introduction}

Spontaneous hemotoraks is defined as blood aggregation due to non-traumatic causes [1]. Depending on the amount of bleeding into thorax, it is classified in three groups, namely $300 \mathrm{~mL}$ and less bleedings minimal hemothorax, $300-1,000$ $\mathrm{mL}$ bleedings mid-level hemothorax, $1,000 \mathrm{~mL}$ and more bleedings massive hemothorax [2]. Pulmonary pathologies, pleural pathologies, lung tumors, stomach pathologies, blood dyscrasia and non-pulmonary intrathoracic pathologies could be the causes of spontaneous hemothorax [3]. It could be widely seen in young ages (average 22.1 and 34.0 years) and often depends on pleural pathologies [4]. The cases whose causes could not be diagnosed are named idiopathic spontaneous hemothorax [5]. Hemodynamic and respiratory changes would be seen based on the amount of hemorrage [6]. It would be diagnosed by various methods such as physical examinations, clinical symptoms, animation methods and endoscopic examinations [2]. Spontaneous hemothorax is mostly treated with tube thoracostomy after diagnosis [7]. Video-assisted thoracoscopic surgery (VATS) is one of the most preferred and recent treatment methods $[8,9]$.

\section{Case Report}

A 17-year-old female patient consulted with the complaints of chest pain on the left side and dyspnea. Patient stated that her chest pain did not change with position, dyspnea decreased by bending over, she had cough and her complaints were increasing gradually. It was learnt that the patient did not have any diagnosed disease previously, did not use any drugs, did not complain with hemoptysis, and did not have fever in that time. 


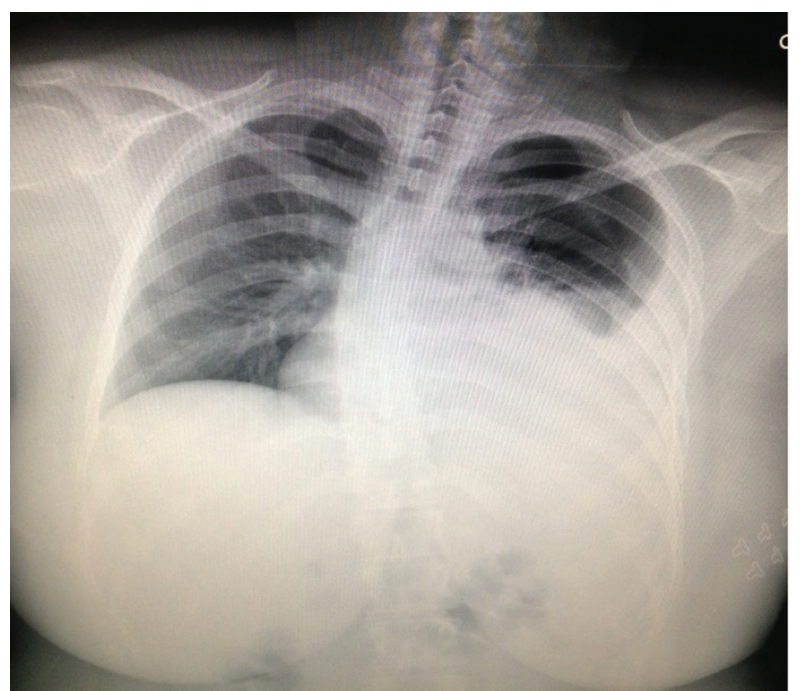

Figure 1. Lung graph findings were compatible with left unilateral hemothorax.

In addition, her family did not have illness and myocardium infarction. Also she did not have similar symptoms previously.

Her blood pressure was in normal level and body temperature was $37.8^{\circ} \mathrm{C}$. She did not have tachypnea and tachycardia. In the lung exam, there was no rhonchi but there was crackles. Other system exams were normal. Lung graph findings were compatible with left unilateral hemothorax (Fig. 1). In computerized tomography, it was found that there were obvious pleural liquids with the depth of $5.5 \mathrm{~cm}$ on the left hemothorax

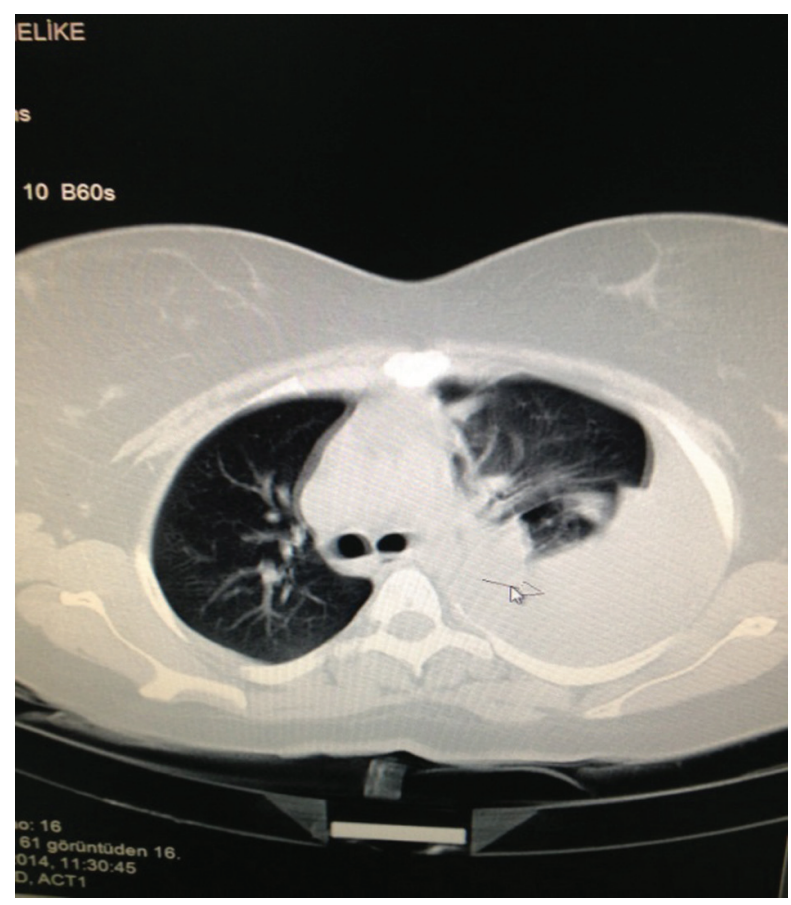

Figure 2. In computerized tomography of parenchymal window, there were obvious pleural liquids with the depth of $5.5 \mathrm{~cm}$ on the left hemothorax and atelectasis in some areas.

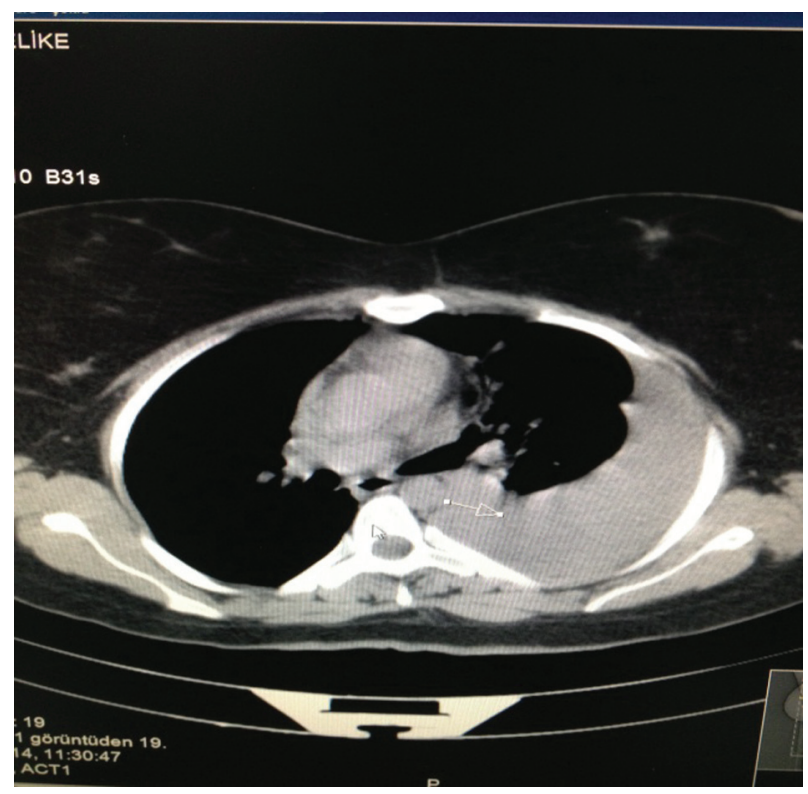

Figure 3. In computerized tomography of bone window, there were pleural liquids with the depth of $5.5 \mathrm{~cm}$ on the left hemothorax.

and there were atelectasis in some areas (Fig. 2, 3). Under the consideration of these circumstances, patient was treated to thoracic medicine services with catheter thoracostomy. With expansion deficiency and inappropriate drainage, the patient was implemented left VATS, pleural biopsy and pleural drainage. Her $\mathrm{Hb}$ levels declined from $11.2 \mathrm{~g} / \mathrm{dL}$ to $10.1 \mathrm{~g} / \mathrm{dL}$. In her VATS report, there were pleural liquids, minimal parenchymal units were seperated, thorax was small and diaphragm was elevated and no substantial pleural and parancimal pathologies were not defined. The sample which was taken from the pleural biopsy was fibrinous ploritis and it was compatible with common fresh bleeding. Cytologic findings was compatible chronic inflammatory reaction.

\section{Discussion}

Hemothorax is mostly seen after obtuse and penetrant traumas $[5,10]$. Spontaneous hemothorax is defined as blood aggregation in pleural zone due to non-traumatic causes [1]. Its symptoms and physical exam findings could be differed related with the reasons of spontaneous hemothorax [11]. Spontaneous hemothorax is an extremely rare disease. It is understood that Sayir and his friends diagnosed five spontaneous hemothorax in 220 patients between 2005 and 2011 and four of these were males and just one of them was female. Also in four cases hemothorax were on the right side and last one was on the left side [12]. As it could be observed from this analysis, spontaneous hemothorax is extremely and rarely seen on the females and left side. However, in this case, patient was female and hemothorax was on the left side. Comparative with frequency of spontaneous hemothorax, frequency of traumatic hemothorax is relatively high [12]. Even though it is seldomly seen with chest pain and dyspnea, spontaneous hemothorax must be con- 
sidered as an option. Usually there is another primary reason beneath it. There could be fatal risk [12]. It is argued that Senturk and his friends treated for spontaneous hemothorax which are caused by various reasons, namely 17 malignant $(8.9 \%)$, two bullous lung $(1 \%)$, two tuberculosis $(1 \%)$, one lung abscess $(0.5 \%)$ in 192 cases [13]. In the bleedings caused by intra-thoracic organs and aorta aneurism rupture, shock symptoms would be found accompanied with serious hemodynamic changes [14-19]. In the spontaneous hemothorax cases which are correlated with metastatic diseases and anticoagulante medicines, there is no fast bleeding into intrapleural zone and hemodynamic changes would not almost be seen. If there is big amount of effusion, dyspnea is significant symptom. Sometimes anemia could be seen [20]. Pneumothorax hemothorax mostly would be seen in the parietal pleura and vascularize visceral seperations which are cohesive pleuritis-pulmonary pathologies [21]. In this case, firstly it was thought that hemothorax was developed due to the chronic fibrinosis pleuritis. However, pnomothorax could not be found in the case.

Treatment of spontaneous hemothorax differs because of the etiology and in most cases tube thoracostomy could not be enough. However thoracotomy must be deployed with more than $200 \mathrm{cc}$ drainage in the situations such as hypovolemic shocks and lung expansions. Recently, VATS has become popular $[8,9]$. In this case, VATS and tube thoracostomy were deployed.

In conclusion, hemothorax is an urgent situation which has to be diagnosed immediately. Awareness of causes is highly helpful to diagnose. Even though it is rarely seen in the patients with chest pain and dyspnea, spontaneous hemothorax has to be considered. Treatment methods have to be decided up to vital indications and tube thoracostomy has to be implemented. In the elective situations in which drainage could not be used, VATS would be thought as an alternative option.

\section{Conflict of Interest}

No conflict of interest was declared by the authors.

\section{References}

1. Bechara R, Ernst A. Medical management of non malignant pleural effusions. In: Sugarbaker DJ, Bueno R, Krasna MJ, Mentzer SJ, Zellos L, eds. Adult Chest Surgery. Newyork: Mc Graw Hill Medical; 2009:912-916.

2. Akay H. Hemotoraksta Tani ve Tedavi Yaklasimi. Solunum. 2002;4(Ek 1):195-205.

3. Hemothorax. In: Light RW, ed. Pleural Diseases. 4th ed. Philadelphia: Lippincott Williams and Wilkins; 2001:320325.

4. Ali HA, Lippmann M, Mundathaje U, Khaleeq G. Spontaneous hemothorax: a comprehensive review. Chest. 2008;134(5):1056-1065.

5. Garcia-Talavera I, Perez Negrin L, Casanova Macario C. [Idiopathic spontaneous hemothorax]. Arch Bronconeu- mol. 2000;36(1):59-60.

6. Zhao Y, Li GY, Yang Z, Zhang P, Zhang K, Shao G. Bilateral heterochronic spontaneous hemothorax caused by pulmonary arteriovenous malformation in a gravid: a case report. J Cardiothorac Surg. 2010;5:96.

7. de Perrot M, Deleaval J, Robert J, Spiliopoulos A. Spontaneous hemopneumothorax--results of conservative treatment. Swiss Surg. 2000;6(2):62-64.

8. Hsu NY, Hsieh MJ, Liu HP, Kao CL, Chang JP, Lin PJ, Chang $\mathrm{CH}$. Video-assisted thoracoscopic surgery for spontaneous hemopneumothorax. World J Surg. 1998;22(1):23-26; discussion 26-27.

9. Tatebe S, Yoshiya K, Yamaguchi A. Video-assisted surgery for spontaneous pneumothorax. Surg Laparasc. Endosc. 1997;7(2):113-115.

10. Battistella FD, Benfield JR. Blunt and penetrating injuries of the chest wall, pleura and lungs. In: Shields TW, Locicero J 3rd, Ponn RB, editors. General thoracic surgery, 5th ed. Philadelphia: Lippincott Williams \& Wilkins. 2000; p. 815-831.

11. Kollef MH. Loculated hemopneumothorax of a major fissure in patients with COPD and associated pleural disease. Chest. 1990;97(4):873-876.

12. Sayir F, Cobanoglu F, Sertogullarindan B, Mergan D. Spontaneous Hemothorax: Analysis of 5 Cases. Journal of Clinical and Analytical Medicine. 2012;3(2):152-154.

13. Senturk E, Yoldas E, Dogan Y. Hemotoraks tedavisi: 192 olgunun degerlendirilmesi. Turk Gogus Kalp Damar Cerrahisi Dergisi. 2009;17(2):92-96.

14. Muraguchi T, Tsukioka K, Hirata S, Fukuda S, Mizugami K, Kishi A, Morimoto Y, et al. Spontaneous hemopneumothorax with aberrant vessels found to be the source of bleeding: report of two cases. Surg Today. 1993;23(12):1119-1123.

15. Edinburgh KJ, Chung MH, Webb WR. CT of spontaneous hemothorax from intrapleural rupture of a pulmonary arteriovenous malformation. AJR Am J Roentgenol. 1998;170(5):1399-1400.

16. Templeton PA, Vainright JR, Rodriguez A, Diaconis JN. Mediastinal tumors presenting as spontaneous hemothorax, simulating aortic dissection. Chest. 1988;93(4):828830.

17. Mori M, Nakanishi N, Furuya K. Hemangiopericytoma of the mediastinum causing spontaneous hemothorax. Ann Thorac Surg. 1994;58(5):1525-1527.

18. Karlawish JH, Smith GW, Gabrielson EW, Liu MC. Spontaneous hemothorax caused by a chest wall chondrosarcoma. Ann Thorac Surg. 1995;59(1):231-233.

19. Teijeira FJ, Baril C, Younge D. Spontaneous hemothorax in a patient with hereditary multiple exostoses. Ann Thorac Surg. 1989;48(5):717-718.

20. De Perrot M, Deleaval J, Robert J, Spiliopoulos A. Spontan hemo pneumothorax results of conservative treatment. Swiss Surg. 2000;6(2):62 -64.

21. Tatebe S, Kanazawa H, Yamazaki Y, Aoki E, Sakurai Y. Spontaneous hemopneumothorax. Ann Thorac Surg. 1996;62(4):1011-1015. 